http://dx.doi.org/10.12795/PH.1988.v03.i01.05

\title{
DEL TEXTO A LA OBRA LITERARIA. PROBLEMAS DE ENUNCIACION EN EL DISCURSO DE FICCION
}

\author{
Manuel Marín Jorge
}

El objeto de este artículo es tratar de esclarecer una cuestión que nos parece previa al estudio de la narración ficticia: saber si se debe legítimamente o no excluir de entre los conceptos teóricos narratológicos las categorías de autor y lector. Antes de responder en un sentido u otro, es necesario determinar qué factores configuran los procesos de enunciación, cosa nada fácil cuando el problema de la ficción interviene de forma ineludible, y en qué medida son constitutivos del sentido de las obras concretas, así como de la diversidad de interpretaciones que la obra literaria suscita.

Nuestra hipótesis es que de dichos procesos forman parte esencial tanto el autor como el lector, en cuanto agentes de la producción y recepción del texto, que, trascendiendo el plano de la representación, objeto de la narración, permiten considerar los elementos narrativos (acción, pensamientos, personajes y voz narrativa) como objetos de configuración de la intriga ${ }^{1} \mathrm{y}$, a través de ellos, ficcionalizar sus «roles comunicativos», haciendo así posible «el contacto con mundos textuales ficticios que poseen una diferencia reconocible respecto a la realidad de experiencia ${ }^{2}$. Al mismo tiempo, las instancias de producción y recepción facilitan la inscripción de las obras concretas en el seno de los sistemas socio-culturales e históricos.

De aquí se deduce que no podemos suscribir la tesis propagada por el formalismo de la autonomía del texto respecto a las condiciones de producción y recepción. En la línea del formalismo más radical, A. Banfield, en una obra

1 P. Ricoeur: Temps et récit, II, La configuration du récit de fiction, Seuil, Paris 1984, p. 148.

2 S. J. Schmidt: «La communication littéraire», en Stratégies discursives, Coord. A. Berrendonner, Presses Univ., Lyon 1978, p. 29. 
reciente, basándose en la observación de que ciertas formas del relato escrito, como el aoristo o el discurso indirecto libre, son casi desconocidas del lenguaje hablado, concluye que, al ser «indecible» (unspeakable), nadie las profiere, y por tanto el autor habría «desaparecido definitivamente del texto»3; el relato sería así «la forma literaria que muestra la estructura del pensamiento moderno» ${ }^{4}$. Esta versión extrema del idealismo formalista no es frecuente. Pero existen otras modalidades que únicamente consideran pertinentes los procedimientos de composición narrativa, desechando las estrategias de comunicación literaria.

\section{Formalismo y comunicación dialógica}

Podría entenderse que lo que pretendemos es resucitar los estudios psicográficos y sociológicos tradicionales. Nada de eso, pues, como vamos a tratar de ver, si la persona del autor y el lector son ciertamente entidades que escapan a la teoría de la literatura, no así los mecanismos y las estrategias textuales que implican su intervención como agentes de la comunicación. Asumimos la crítica formulada hace casi sesenta años por M. Bakhtine al «objetivismo abstracto» ${ }^{5}$ de Saussure, con quien tanto tiene que ver la concepción autotélica del lenguaje literario, en el sentido que la lengua se concibe como un sistema de normas exteriores a los sujetos del habla. Para Bakhtine, por el contrario, el lenguaje consiste «en la comunicación verbal concreta, no en el sistema lingüístico abstracto de las formas de la lengua, ni en el psiquismo individual de los hablantes» ${ }^{6}$.

En pleno apogeo del formalismo ruso y del subjetivismo individualista representado por Vossler, que se inspira en Humboldt, Bakhtine rechaza ambas posturas, sosteniendo que «la situación social más inmediata y el medio social más amplio determinan enteramente, y ello desde el interior, por así decir, la estructura de la enunciación» ${ }^{7}$. El concepto de «dialogismo», acuñado por él, supone que las palabras y los enunciados son el dominio común del locutor y del interlocutor.

La vía abierta por Bakhtine será durante décadas ignorada hasta que estudios posteriores, que tienen por objeto la actividad significante como determinante del empleo de las formas, inscritas en el sistema de la lengua, vuelvan a reflexionar sobre los presupuestos básicos del estudio del discurso y del texto, literario o no. Existen, sin embargo, dentro del mismo formalismo, tendencias antagónicas, una de las cuales es precisamente la aproximación, más o menos decidida, de las estrategias de comunicación literaria.

3 A. BANFIELD: Unspeakable Sentences: Narration and Representation in the Language of Fiction, Routledge \& Kegan Paul, Boston-London 1984, p. 222.

Ibid., p. 254.

5 M. BAKHTINE (V. N. Volochinov): Le marxisme et la philosophie du langage; essai d'application de la méthode sociologique en linguistique, Leningrado 1929 (Tad. francesa, 1977, Ed. de Minuit).

6 Ibid., p. 137.

7 Ibid., p. 124. 
Frente a la tradición determinista del positivismo y del marxismo vulgar, que tratan de reducir la obra ya a un mero reflejo de las condiciones materiales (medio geográfico, raza o grupo social), ya a una simple cuestión de superestructura ideológica de clase, el formalismo, en sus diversas vertientes, tiende a desvalorizar la relación entre las obras y lo que éstas designan, expresan o enseñan, así como la relación que se establece entre las obras y los sujetos de producción y de recepción, poniendo, en cambio, el énfasis en la estructura de la obra misma y en la articulación de sus episodios, temas e imágenes.

Aunque nos referimos esencialmente al formalismo ruso y al estructuralismo europeo, la Nueva Crítica norteamericana coincide, en líneas generales, con dichas corrientes formalistas. En efecto, desde los años treinta, rechazan como pertinentes para el análisis literario, todo recurso a la historia, al autor y a sus intenciones-intentional fallacy - más o menos explícitas, así como a cualquier contenido referencial o respecto a cualquier consideración que conduzca al autor y al lector reales.

La idea del autotelismo como definición del arte procede directamente de los escritos que sobre estética escribieron Karl Philipp Moritz y Kant. El primero declara, por ejemplo, que la ausencia de finalidad externa del arte, debe ser compensada por la intensificación de la finalidad interna ${ }^{8}$. En cuanto a Kant, si bien es cierto que erigió la actividad estética en instancia mediadora entre la naturaleza y la libertad, entre la sensibilidad y la razón, también lo es que negó al juicio estético cualquier finalidad que no fuera normal, «es decir sin fin» ${ }^{9}$, así como toda función cognitiva.

De manera general, al menos en sus inicios, el formalismo ruso, que se inspira en la filosofía estética del romanticismo alemán (Schlegel, Novalis, Schelling) y en el simbolismo (Mallarmé y los simbolistas rusos), penetrados a su vez por la estética de Kant, pretende circunscribir la especificidad literaria, objetivándola en sus componentes semióticos, sobre todo en las estructuras fonológicas del lenguaje. Pero del grupo formalista quien con más persistencia mantuvo los principios iniciales fue, sin duda, R. Jakobson. Todavía en 1960 ${ }^{10}$, en el curso de unas conferencias interdisciplinarias, sostenía la posibilidad de establecer una definición estructural (lingüística y transhistórica) si no de la poesía, al menos de lo que denominó «función poética», «dominante» y «determinante» en la poesía por encima de las otras funciones. Lo que caracteriza a esta función es el «acento puesto en el mensaje mismo»" ${ }^{11}$. Esta concepción inmanente de la poética evoca la de uno de sus maestros, Saussure, que en el Curso sostiene que la lengua debe ser descrita «en elle-même et pour ellemême». Jakobson funda así la «gramática» de la poesía. Otros autores intentarán lo mismo en el dominio del relato.

8 T. Todorov: Critique de la critique, Seuil, Paris 1984, p. 24-25.

9 E. Kant: Critique de la faculté de juger, Traduc. francesa de A. Philonenko, Vrin, Paris 1979 , p. 68.

10 R. Jakobson: Essais de linguistique générale. Trad. francesa de N. Ruwet, Seuil Col. Points, Paris 1963, pp. 209-248.

11 Ibid., p. 218. 
La evolución de otros componentes del grupo diverge notablemente de la posición de Jakobson, en especial la de Chilovski y Tynianov. Este último sostiene, por ejemplo, a finales de los años veinte, que «el hecho literario es heterogéneo, y en ese sentido la literatura es una serie que evoluciona con solución de continuidad» ${ }^{12}$. Piensa Todorov que Tynianov «desposee a la literatura de su lugar excepcional, al considerarla no ya en oposición, sino en relación de intercambio y de transformación con los otros géneros del discurso» ${ }^{13}$.

La concepción autotélica del lenguaje poético a partir de la función poética posee, aparentemente, un valor explicativo que incluye en su ámbito, además de la poesía, los géneros literarios inscritos en la ficción, como el cuento. En efecto, «la supremacía de la función poética sobre la función referencial no oblitera la referencia (denotación), sino que la hace ambigua» ${ }^{14}$. Quiere esto decir que las demás funciones se alteran, desdoblándose, incluida la función referencial, como se observa en el exordio de los narradores mallorquines: «Aixo era y no era».

De ser esto cierto, es decir, el sincretismo de lo ficticio y lo literario o poético, el principio inmanentista de Jakobson ofrecería, con gran economía de medios, un único criterio de análisis capaz de dar cuenta de cualquier producto literario. ¿Pero es acaso correcta dicha asimilación? ¿Obedecen a un mismo principio lógico ambos conceptos?

\section{Ficción como simulación}

J. Searle ${ }^{15}$, que ha afrontado estos problemas desde la perspectiva pragmática de los actos ilocutivos, toma ciertas precauciones para delimitar ambos conceptos. El hecho de que la mayoría de las obras literarias sean ficticias puede inducir a pensar, confundiendo la definición de ficción y la definición de lo literario, que una y otra son la misma $\operatorname{cosa}^{16}$. Ahora bien, todos sabemos que existen obras de ficción que no son consideradas como literarias y viceversa, obras tenidas por literarias que no son ficticias.

Sólo la ficción es susceptible de ser definida lógicamente, no así la literatura, y ello por tres razones: a) porque no existe un conjunto de rasgos que, pudiendo constituir las condiciones necesarias y suficientes, sea común a todas las obras literarias; lo literario, todo lo más, podría asociarse con la noción, acuñada por Wittgenstein, de semejanza de familia (family resemblance); b) porque el término de «literatura» aglutina un conjunto de actitudes que asumismos ante ciertas secuencias de discurso, aunque no se desecha que procedan, en parte, de propiedades del discurso mismo, razón por la que no pueden considerarse totalmente arbitrarias; c) en fin, porque lo literario forma un

12 Citado por Todorov, ob. cit., p. 35.

13 T. TODOROV, ob. cit. p. 37.

14 R. JAKOBSON, ob. cit. p. 238.

15 J. SEARLE: «The logical Status of Fiction», en Expression and meaning, Cambridge Univ. Press, Cambridge 1979, pp. 58-75.

16 Ibid., p. 59. 
todo continuo con lo no literario, fenómeno que, como vimos, había puesto ya de relieve Tynianov.

En el caso de la comunicación mediante enunciados ficticios, la cuestión fundamental es saber qué es lo que hace posible que un autor, utilizando las palabras de manera literal, no esté obligado a respetar las reglas que implícitamente rigen en los casos de la interpretación de esas mismas palabras en discursos no ficticios. La respuesta es que, así como una aserción es un tipo de acto ilocutivo que se conforma a una serie de reglas semánticas y pragmáticas específicas, en cambio, cuando se trata de un discurso de ficción, esas reglas, sin ser exactamente infringidas, son en cierto modo «simuladas» (pretended) ${ }^{17}$. No debe inferirse de ello que el escritor o el narrador pretendan decepcionar o mentir al lector o al oyente: se trata más bien de una simulación manifiesta o pública, una especie de juego, una acción lúdica relacionada con una realidad cultural previa, con unas reglas convencionales que los participantes en este tipo de interacción respetan de común acuerdo. De aquí se desprende una segunda propiedad de este tipo de discurso: la simulación, el «como si» de la acción fingida es, por su carácter público, un acto intencional. Por eso, en su nivel más profundo, piensa Searle ${ }^{18}$ que sería absurdo suponer que un crítico pueda ignorar, en este dominio, las intenciones del autor. Toma, así, posición contra ciertos dogmatismos que califican de falaces los juicios que se basan en la intención del autor.

Mas, si no existen indicativos lingüísticos de ficción directamente incorporados al texto, ni se explicita, como en el exordio de los narradores mallorquines, metalingüísticamente el tipo de elocución, ¿qué es lo que hace posible que comprendamos sin dificultad y reconozcamos los textos de ficción, aun los más «realistas» desde el punto de vista de la mímesis referencial? La ficción es posible gracias a un conjunto de convenciones extralingüísticas que suspenden la conexión establecida por las reglas semánticas y pragmáticas entre los enunciados y el mundo. Ese conjunto de convenciones, Searle lo denomina «horizontal», para diferenciarlo del conjunto de «reglas verticales» con que designa las reglas semánticas. «Las convenciones horizontales no son reglas de significación, no forman parte de la competencia semántica del hablante. Por tanto no alteran o cambian el sentido de ninguna de las palabras u otros elementos del lenguaje» ${ }^{19}$. Contar historias, en este sentido, sería un «juego del lenguaje», distinto de otras formas de discurso que, eventualmente, puede superponerse parasitariamente a ellas. No por eso la ficción es una mentira. La mentira es una violación de las reglas pragmáticas y semánticas que son inherentes al discurso ordinario, la ficción, en cambio, que no las conculca, simplemente las simula.

Desde Aristóteles, el modelo que mejor ilustra las propiedades del discurso de ficción es el modelo teatral, imitación-simulación de acciones, en las que se

17 Ibid, p. 65.

18 Ibid, p. 66.

19 Ibid, p. 67. 
anuda una intriga. Es importante señalar los dos hechos fundamentales de la mímesis teatral: la simulación o imitación creativa de la experiencia con intención de comunicarla a los espectadores y el carácter de ordenación de lo diverso en una historia (intriga). Sólo me voy a fijar en el primero de los rasgos. Como dice Rainer Warning ${ }^{20}$ : «Por una lado hay una situación interna de enunciación con locutor(es) y destinatario(s), por otro, una situación externa de recepción que tiene de singular, frente a la situación interna de enunciación, que el destinatario se ve privado de la relación dialógica con un locutor real (...)», pero el «locutor real, el autor, se disemina en los roles de los personajes de ficción, incluido, en los géneros narrativos, el narrador». Esto no supone que el autor se haya evaporado en la acción simulada, sino que guarda, por así decir, un pie en el universo definido por la representación mimética, mientras escribe, y otro en el mundo real; la experiencia como sujeto de la simulación le permite indicar el modo eventual de la realización escénica, mediante acotaciones escénicas. También el universo del espectador es doble: uno imaginario y otro real.

Así, lejos de que el discurso de ficción proceda de los efectos de la «función poética», es la actividad interactiva, sustentada en una realidad cultural previa y en la situación más inmediata de la relación dialógica diferida, la que lo determina. Precisamente, la realidad cultural previa, de la que participa el público (-lector) es donde se fundan las convenciones y paradigmas de interpretación, que son los géneros, donde se determina, en confluencia con el texto, la ambigüedad origen de la referencia desdoblada. Como en otro momento dice Warning ${ }^{21}$, «el sentido de la ficción, por ambiguo y polivalente que sea, se halla inscrito en la identidad del texto en cuanto discurso situado. El autor, que puede estar ausente en cuanto locutor real, está sin embargo presente en forma de convenciones pragmáticas y semánticas, que respetadas o no, organizan el discurso». La convención pragmática más relevante sería, en este caso, precisamente, la instrucción explícita o implícita de descodificación del desdoblamiento referencial, incluidos el autor y el lector. El discurso de ficción más que alterar la identidad de la ejecución lingüística la promueve, de tal modo que «situación interna de enunciación y situación externa de recepción representan los dos extremos de una confrontación constitutiva de una situación de comunicación homogénea. En ese sentido, la ficción es esencialmente contractual y, por lo mismo, histórica» ${ }^{22}$.

Queda aún por ver cómo se articulan, en cuanto conceptos diferentes, ficción y literatura, a qué dominios pertenecen estos conceptos y, en fin, aunque ya esbozada, cuál es la función que autor y lector desempeñan en la conversión del texto en obra acabada.

20 R. Warning (1979), «Pour une pragmatique du discours fictionnel», en Poétique, 39, p. 328.

21 Ibid.

22 Ibid. 


\section{Composición y comunicación literaria}

En su propósito legítimo de formalizar los fenómenos del discurso literario en un objeto teórico y de conocimiento, la teoría y la crítica estructuralista, al concentrar primordialmente su atención en las formas de expresión y de contenido, ha terminado reificando el mensaje, «esta reificación del mensaje poético y de sus elementos constitutivos(...) representa una propiedad intrínseca y eficiente de la poesía» ${ }^{23}$. En cambio, ha dejado frecuentemente de lado los procesos de significación y su relación con el contexto y los destinatarios del discurso, o los ha neutralizado, objetivándolos en las instancias de representación diegética, como es el caso frecuente de la narratología casi exclusivamente entregada al texto de ficción.

Al ser tributario de una teoría lingüística que disocia en dos planos irreconciliables, los elementos normales de significación, fonológicos y morfosintácticos, de los actos de habla, supuestamente asistemáticos, el estructuralismo ha privilegiado las relaciones semióticas inmanentes de los signos a expensas de lo que A. Culioli ${ }^{24}$ define como propio de la lengua en su relación necesaria con la actividad del lenguaje, a saber: «actividad de regulación intersubjetiva (entre sujetos en su singularidad histórica, psíquica y social) y transindividual (cohesión institucional, conductas de grupo, ritos, juegos de lenguaje), y como actividad de representación». Como proceso, como «imagen de la enunciación» ${ }^{25}$, el enunciado y, por tanto el texto, remite a los agentes del discurso en su relación interactiva e ilocutiva. Si esto es cierto no caben alternativas simplificadoras como la que propone el formalismo reificando el mensaje como forma autónoma y transcendente, o, a la inversa, la que practica el realismo ingenuo, que reduce la relación referencial a la remisión hacia una realidad objetiva y estable. La enunciación como proceso de interacción no admite un esquema simplista y estático entre interlocutores transparentes, tal como se representa, por ejemplo, en el «circuito de comunicación» saussureano, o en el algo menos simple de la teoría matemática de la comunicación de Shanon y Weaver (1949). Modelo, éste último, que tiene muy poca semejanza con el desarrollo de la interacción verbal real, pero que ha servido de modelo a numerosas conceptualizaciones lingüísticas, entre ellas la que Jakobson propone de las funciones del lenguaje.

Probablemente sea W. C. Booth con su obra Rhetoric of Fiction ${ }^{26}$, recientemente reeditada, quien más eficazmente ha contribuido a establecer los primeros fundamentos de una teoría donde el discurso de ficción y la persuasión se interrelacionan, rompiendo con ello la clausura a la que los análisis de las estructuras inmanentes del lenguaje sometían al texto literario. Es mérito de

3 R. JAKobSON, ob. cit., p. 239.

24 A. Culioli: «En guise d'introduction», en La langue au ras du texte. Bajo la dir. de A. Gésillon y J. L. Lebrave, Presses Univ. de Lille, p. 9.

25 O. Ducrot et al.: Les mots du discours, Minuit, Paris 1980, p. 35.

26 W. C. Воотн: The Rhetoric of Fiction, Un. Press, Chicago 1961 (2. ${ }^{a}$ ed. con postfacio, 1983). 
este autor, miembro del grupo neo-aristotélico de Chicago, conocido por su clasificación de los «puntos de vista» narrativos, el haber introducido, en teoría literaria, el concepto de autor implicado (implied author) y, a través de él, una perspectiva nueva de la perspectiva estética del texto, que, sin regresar al psicobiografismo de viejo cuño, permite articular la teoría poética de la composición y la teoría de la comunicación literaria.

Con la lectura, complemento de la escritura, la obra adquiere su finalidad. El carácter teleológico del texto, que se completa en la obra leída, presupone un circuito que empieza en el autor, atraviesa el texto y concluye en el lector. Evidentemente, esto es una abstracción cómoda pero simplista de la interacción entre lectura y escritura por lo que luego diremos. Sin embargo nos permite ya entender la afirmación categórica de Proust, según la cual al estilo es «una cuestión no de técnica sino de visión», orientando así las cuestiones estéticas desde una perspectiva de la acción. No se trata por tanto de la relación exclusiva del autor con la obra: el juicio estético se completa en la actividad crítica de recepción. La obra adquiere así carácter de acontecimiento y plena significación histórica, social y estética. Sin la noción de autor implicado, afirma S. Rimmon ${ }^{27}$, sería difícil analizar las «normas» del texto cuando éstas difieren de las del narrador. No creemos sin embargo que su función sea, como sostiene polémicamente Genette ${ }^{28}$, que excluye dicha categoría de la teoría narratológica, en beneficio del narrador ficticio, «esencialmente ideológica». Además, o al mismo tiempo que una función ideológica, desempeña otras difícilmente jerarquizables, como la ya señalada, función estilística que concierne tanto a los aspectos compositivos como de persuasión, amén de otras que aquí no es el momento de enumerar y ponderar su valor, en la relación del texto con la actividad lectora y crítica. Imagen del autor real, previa a su ficcionalización en el rol de voz narrativa en el cuento, la novela corta o la novela, construida por el texto y percibida como tal por el lector, el autor implicado permite además al lector evaluar el propio discurso ficticio de la obra concreta según criterios y reglas originados por la lectura de otros textos concretos, así como las normas que proceden de los géneros constituidos en el transcurso histórico.

Son, en efecto, esas normas y los paradigmas genéricos lo que constituye, según H. R. Jauss ${ }^{29}$, que toma la expresión de Husserl, el «horizonte de expectativas» o «sistema de referencias objetivamente formulables que, para cada obra en el momento de la historia en que aparece, es el resultado de tres factores principales: la experiencia previa que el público tiene del género del que depende, la forma y la temática de obras anteriores de las que presupone el conocimiento, y la oposición entre lenguaje poético y lenguaje práctico, mundo imaginario y realidad cotidiana».

27 S. Rimmon: «A Comprehensive Theory of Narrative» PTL, i, i, 1976, p: 58.

28 G. Genette: Nouveau discous du récit, Seuil, Paris 1983, p. 97.

29 H. R. JAuss: Pour une esthétique de la réception, Prefacio de J. Starobinski, Gallimard, Paris 1978, p. 49. 
Según esta perspectiva, la ficción, de acuerdo también con Searle, obedece a principios antropológicos y culturales que no dependen de las estructuras de la gramática ni de la semántica del texto. Pero si es el lector quien decide de los valores literarios de la obra es el autor quien, sin embargo, toma la iniciativa de que el discurso sea o no ficticio ${ }^{30}$.

Para concluir con la cuestión de la categoría de autor implicado, diremos, siguiendo a P. Ricoeur ${ }^{31}$, en su comentario de Booth, que, situadas en el marco de la comunicación, ciertas querellas sobre la importancia de los esfuerzos del novelista moderno por borrarse de la obra como autor, no son pertinentes. No por «desaparecer» la novela deja de tener autor. La actitud de ocultación del autor debe contarse entre las técnicas retóricas; como la presencia, es otra técnica pero de sentido inverso, es decir de manifestación de sí mismo por parte del autor que puede tener, en ambos casos, un sentido ético, pero no necesariamente; convención, esta última, explotada por autores clásicos, como Sterne y Diderot en Tristram Shandy y Jacques le Fataliste et son maître, pero también de autores modernos, como Proust en $A$ la recherche du temps perdu, que no tuvieron empacho en indicar el carácter ficticio de sus obras y jugar con la distancia que, como autores, les separa de la máscara del narrador. Otro tanto se puede decir del derecho que el autor se arroga cuando describe a sus personajes desde el interior: lugar común que Proust, por ejemplo, analiza desde la doble perspectiva de autor y de lector ${ }^{32}$.

«La trouvaille du romancier a été d'avoir l'idée de remplacer ces parties impénétrables à l'âme por una quantité égale de parties immatérielles, c'est-à-dire que notre âme peut s'assimiler. Qu'importe dès lors que les actions, les émotions de ces êtres d'un noveau genre nous apparaissent comme vrais, puisque nous les avons faites nôtres, puisque c'est en nous qu'elles se produisent, qu'elles tiennent sous leur dépendance, tandis que nous tournons fiévreusement las pages du livre, la rapidité de nôtre regard?

En la lectura cabe una dimensión cooperativa crítica, donde la interacción del lector con la obra de un autor puede asociarse con la producción de otras obras del mismo autor o de otros autores y géneros. El lector coopera entonces con el autor para que la obra sea, además de una totalidad unificada a nivel de las reglas de composición, la elección y la realización de normas que hacen del texto la obra de la enunciación y no de la naturaleza. Mantiene Ricoeur ${ }^{33}$ que ese papel unificador que el lector atribuye al autor se puede designar con la noción de estilo tal como G. Granger propone en su Essai d'une philosophie du style (1968). «Si se considera una obra, comenta Ricoeur, como la resolución de un problema, surgido él mismo de anteriores logros en el dominio de la

J. SEARLE: art. cit., p. 59.

P. Ricoeur: Temps et récit, III, Seuil, Paris 1985, p. 233.

32 M. Proust: A la recherche du temps perdu, Gallimard, Pléiade, 1954, p. T. I, p. 85.

33 P. Ricoeur, Ob. cit., 1985, p.235. 
ciencia como en el arte, se puede llamar estilo a la adecuación entre la singularidad de la solución que constituye en sí misma la obra y la singularidad de la coyuntura de la crisis, tal como el pensador o el artista la ha aprendido. La singularidad de la solución que responde a la peculiaridad del problema puede recibir un nombre propio, el de autor».

La cuestión relativa a la categorización del autor como noción de teoría literaria no es, por lo tanto, una noción psicológica, sino un concepto que procede de la conceptualización de la misma acción. Postular un autor, real esta vez, como organizador de los materiales verbales, poéticos o narrativos, no es una quimera, como lo es por el contrario atribuir esa función al narrador de la ficción, a la manera de Genette ${ }^{34}$.

En la interacción viva entre escritura y lectura, y no en la relación unidireccional, pasiva, del lector que se anula en la representación imaginaria, una misma instancia realiza tareas complementarias. Un mismo autor dialoga críticamente con su propia obra y con las obras del repertorio cultural, un mismo crítico transita como lector por los dominios de la intratextualidad y la intertextualidad; todo escritor es antes un lector y un crítico. La lectura creativa establece una relación dialógica (dialogish), y no conversacional, como en su momento Proust reprochó a cierto esteta británico, con el contexto ideológico, cultural e histórico, además de y a través del texto. Aunque Jauss, en su Estética de la recepción sólo nombra al lector, su indagación ulterior tiende a no convertirse sólo en eso. La tríada poiesis, aisthesis y mimesis también son dialógicas. Con respecto a la relación intertextual, concepto puesto en circulación por los formalismos para deslindar el terreno con la crítica de fuentes, Jauss dice lo siguiente:

«Le lecteur qui jouit et qui juge, qui pose des questions et formule des réponses, ce lecteur qui finalement se met à écrire, c'est la seule instante médiatrice dans le prétendu «dialogue des oeuvres». Sans son intervention active, toute intertextualité, entendue au sens de la théorie dominante comme «dialogue des textes entre eux», resterait illusion idéaliste $(\ldots)^{35}$ »

35 H. R. JAUSS: «Sur l'expérience esthétique en général et litéraire en particulier», Entrevista con Ch. Grivel, en Revue de Sciences Humaines, 1980, n. ${ }^{\circ}$ 177, p. 10. 